\title{
Selected Anatomical Properties of Boscia angustifolia Wood
}

\author{
Olaoye K.O., \\ Okanlawon F.B., \\ Fayanjuola A.L.,
}

Federal College of Forestry, Forestry Research Institute of Nigeria, Nigeria

Doi: 10.19044/esj.2019.v15n12p11 ＵRL:http://dx.doi.org/10.19044/esj.2019.v15n12p11

\begin{abstract}
Microscopic structure of wood is identifiable with anatomy characteristics of the wood, thus the potential utility of a wood is technically dependent upon its anatomical properties. Boscia angustifolia is a lesser used species whose anatomical properties are needed to be exploited so as to known its potential utilization and peculiarity. This research therefore studied some anatomical properties of the species. Four trees were felled, and samples of $20 \times 20 \times 20 \mathrm{~mm}$ were obtained along the sampling height and radial position of the trees. Maceration and sectioning were done on the test samples, after which microscopic structure was viewed under the microscope. Mean fibre characteristics obtained (fibre length - $1.12 \pm 0.24$, fibre diameter $-23.67 \pm 3.05 \mu \mathrm{m}$, lumen width $-10.09 \pm 0.76 \mu \mathrm{m}$, and cell wall thickness $6.87 \pm 1.65 \mu \mathrm{m}$ ) were similar to those of the commonly used hardwood species in Nigeria, and vessel diameter was $65.61 \pm 8.64 \mu \mathrm{m}$, ray height was $294.65 \pm 14.12 \mu \mathrm{m}$ and ray width was $49.32 \pm 19.23 \mu \mathrm{m}$. The selected anatomical properties tested for Boscia angustifolia suggest that it has medium to high density, and can be used for structural purpose.
\end{abstract}

Keywords: Anatomical properties, Boscia angustifolia, vessel, ray, fibre

\section{Introduction}

Wood anatomy is concerned with the study of wood macroscopic structure (that is the features which are visible to the naked eye) and its microscopic structure (features which are only visible under the microscopes). It also investigates the relationship between different cells and their structure which may eventually lead to the identification of woods and their classes (Brian, 2010). The composition of wood makes wood to be an outstanding material; it is versatile, inexhaustible and renewable. These properties have made wood useful in various ways and forms. Over the decades, the demand 
for wood and wood products all over the world has continued to increase (Hickey, 2001).

Boscia angustifolia belongs to the family Capparaceae. It is a shrub or small tree of about $6 \mathrm{~m}$ high with a contorted fluted bole, commonly found in the dry savanna of the northern Region, often on termite mounds from Senegal to Niger and Northern Nigeria, and across Africa to Sudan, Ethiopia, East and South Tropical Africa and Arabia. Its common name in Nigeria is fula-fulfulde (Hausa) (Burkill, 1985), and Ilaoro (Yoruba).

Boscia angustifolia is a lesser used wood species (LUWS) in Nigeria. However, there is less information about it, such as the anatomical properties, thus limiting its application for structural, construction, furniture, and other general purposes.

According to FAO, (1998), the potential utility of any wood is dependent upon its basic anatomical and mechanical properties. These properties are the underlying factors determining the behaviour and recommendation of wood for general uses. The success of LUWS in the timber market requires technical information that relates to utilization about the species (Poku et al., 2001). It is therefore imperative that the provision of technical information on this species is necessary as this will enhance its success and acceptability in the timber market. Therefore, there is need to study the anatomical properties of Boscia angustifolia in order to avail us the necessary behavioural and technical information needed to recommend the species for peculiar uses.

Also, knowledge in the anatomy of wood and its fibre characteristics is essential for assessing certain properties of wood for the purposes of identification, relationship to strength, seasoning, preservative absorption, wood working and pulping properties of the wood, and thus give a guide to wood utilization in service as an engineering material. In turn, it will reduce pressure on the already known and used wood species, thus saving such species from total depletion.

The general objective of this study is to assess the anatomical properties of Boscia angustifolia with a view to determining its potential for general and peculiar uses.

\section{Materials and Method}

Four trees were felled, bucked and cut into merchantable height: From the felled logs, wood samples of $20 \times 20$ x 20mm were obtained axially (base, middle and top wood) and radially (inner, middle and outer) for anatomical test, using circular machine and planning machine. The wood samples were taken to wood anatomy laboratory, Department of Forest Product Development and Utilization Department (FPD \& U), Forestry Research 
Institute of Nigeria (FRIN,) Ibadan, Nigeria where necessary anatomical tests were carried out.

The fibre measurements were conducted in accordance with ASTM D 1030-95 (2007) and ASTM D 1413-61 (2007). Maceration of the slivers was carried out using acetic acid and hydrogen peroxide $(1: 1)$ and placed in an oven for 2 hours at a temperature of $100^{\circ} \mathrm{C}$, then the solution was vigorously agitated for individual fibres to be separated. The macerated fibres were randomly selected and dropped on a standard slide, $7.5 \mathrm{~cm} \times 2.5 \mathrm{~cm}$ using a procedure adopted by Dutt et al. (2012). All the characteristics, namely fibre length (FL), fibre diameter (FD), lumen width (LW) were viewed under a stage micrometer mounted on a Zeiss light microscope (Standard of 25 fibres) under $80 \times$ in swollen state, and cell wall was calculated using eq. 1. Twenty five (25) fibres were measured from each sample slide.

For micrographic analysis (Sectioning), the wooden blocks were soaked in water for 17-24 hours to soften for easy sectioning based on the density of the wood. The wood blocks were oriented to show these dimensional planes or axes: transverse, tangential and radial sections. The sections were $0.02 \mathrm{~mm}$ thick wood in size.

However the steps taken in slides preparation were:

- $\quad$ Sections were stained with Safranine O for 30 minutes and then rinsed in water. The sections were immersed in $50 \%$ and $95 \%$ Ethanol. The ethanol was used to extract the excess staining on the sections.

- Ethanol solvent was cleared by covering the sections with several drops of clove oil for about 5 minutes.

- Sections were transferred into xylene. The process of immersing into xylene solvent is called dehydration and differentiation process.

- Sections were mounted on the slides with the use of Canada balsam. The function of the Canada balsam is to help place the cells intact, without shrinking or collapsing for a very long period and to be seen clearly (IAWA, 1989). Descriptive terminology and measurements followed Quilhó et al. (2004) and List of Microscopic Features for Hardwood Identification (IAWA Committee, 1989).

Lastly, sample representative was selected and examined under the microscope in order to view the cell differentiation of the species along the dimensional planes (transverse, tangential and radial sections) and the photomicrographs for rays and vessels were taken, measured and counted. Ten (10) rays and vessels were measured (length and width).

Thus, ray height, ray width, vessel diameter were measured.

$$
C W T=\frac{F D-L W}{2}
$$




\section{Results and Discussion}

Table 1 and 2 showed the axial and radial variation of fibre characteristics of Boscia angustifolia wood respectively. Pooled mean for fibre length (FL) was $1.14 \pm 0.03 \mathrm{~mm}$, while Fibre diameter (FD) was 24.24 $\pm 2.90 \mu \mathrm{m}$, Lumen width (LW) was $10.37 \pm 1.78 \mu \mathrm{m}$ and Cell wall thickness was $6.99 \pm 1.45 \mu \mathrm{m}$. Meanwhile, axial and radial variation of vessel diameter, ray height and ray width were presented in Table 4 and 5 respectively. Pooled mean value for vessel diameter was $65.61 \pm 8.64 \mu \mathrm{m}$ while ray height was $294.65 \pm 14.12 \mu \mathrm{m}$ and ray width was $49.32 \pm 19.23 \mu \mathrm{m}$. Fig. 1 shows tangential view of the specie's micrograph.

Table 1: Axial Variation of Fibre Characteristics of Boscia angustifolia Wood

\begin{tabular}{|c|c|c|c|c|c|}
\hline SH & $\mathbf{R P}$ & FL (mm) & FD $(\mu \mathrm{m})$ & $\mathbf{L W}(\boldsymbol{\mu m})$ & CWT $(\mu \mathrm{m})$ \\
\hline \multirow{3}{*}{ TOP } & Outer & 1.16 & 26.73 & 10.54 & 8.02 \\
\hline & Middle & 1.14 & 28.97 & 11.53 & 8.72 \\
\hline & Inner & 1.18 & 25.10 & 11.63 & 6.72 \\
\hline \multirow[t]{2}{*}{ Mean } & & $1.16 \pm 0.02$ & $26.94 \pm 1.99$ & $11.23 \pm 2.14$ & $8.02 \pm 1.15$ \\
\hline & Outer & 1.17 & 22.34 & 10.95 & 5.69 \\
\hline \multirow[t]{2}{*}{ MIDDLE } & Middle & 1.12 & 22.75 & 9.44 & 6.65 \\
\hline & Inner & 1.17 & 22.13 & 9.01 & 6.56 \\
\hline \multirow[t]{2}{*}{ Mean } & & $1.15 \pm 0.32$ & $22.41 \pm 0.52$ & $9.80 \pm 1.92$ & $6.30 \pm 0.93$ \\
\hline & Outer & 1.13 & 23.99 & 9.38 & 7.32 \\
\hline \multirow[t]{2}{*}{ BASE } & Middle & 1.09 & 24.32 & 10.68 & 7.50 \\
\hline & Inner & 1.14 & 21.80 & 10.23 & 5.79 \\
\hline Mean & & $1.12 \pm 0.24$ & $23.67 \pm 3.05$ & $10.09+0.76$ & $6.87 \pm I .65$ \\
\hline P. Mean & & $1.14 \pm 0.03$ & $24.24 \pm 2.90$ & $10.37 \pm 1.78$ & $6.99 \pm 1.45$ \\
\hline
\end{tabular}

Table 2: Radial Variation of Fibre Characteristics of Boscia angustifolia Wood

\begin{tabular}{cccccc}
\hline RP & SH & FL $(\mathbf{m m})$ & FD $(\boldsymbol{\mu m})$ & $\mathbf{L W}(\boldsymbol{\mu m})$ & CWT $(\boldsymbol{\mu m})$ \\
\hline \multirow{3}{*}{ OUTER } & Top & 1.16 & 26.73 & 10.54 & 8.02 \\
& Middle & 1.17 & 22.34 & 10.95 & 5.69 \\
Mean & Base & 1.13 & 23.99 & 9.38 & 7.32 \\
& & $\mathbf{1 . 1 6} \pm \mathbf{0 . 0 2}$ & $\mathbf{2 4 . 3 5} \pm \mathbf{2 . 9 8}$ & $\mathbf{1 0 . 2 9} \pm \mathbf{2 . 1 8}$ & $\mathbf{7 . 0 1} \pm \mathbf{1 . 8 3}$ \\
MIDDLE & Top & 1.14 & 28.97 & 11.53 & 8.72 \\
& Middle & 1.12 & 22.75 & 9.44 & 6.65 \\
Mean & Base & 1.09 & 24.32 & 10.68 & 7.50 \\
& & $\mathbf{1 . 1 2} \pm \mathbf{0 . 2 3}$ & $\mathbf{2 5 . 3 5} \pm \mathbf{3 . 2 9}$ & $\mathbf{1 0 . 5 5 + 0 . 9 6}$ & $\mathbf{7 . 6 3} \pm \mathbf{1 . 2 0}$ \\
INNER & Top & 1.18 & 25.10 & 11.63 & 6.72 \\
& Middle & 1.17 & 22.13 & 9.01 & 6.56 \\
Mean & Base & 1.14 & 21.80 & 10.23 & 5.79 \\
P. Mean & & $\mathbf{1 . 1 6} \pm \mathbf{0 . 0 2}$ & $\mathbf{2 3 . 0 1} \pm \mathbf{1 . 7 9}$ & $\mathbf{1 0 . 2 9} \pm \mathbf{2 . 0 7}$ & $\mathbf{6 . 3 6} \pm \mathbf{1 . 0 1}$ \\
& & $\mathbf{1 . 1 4} \mathbf{0 . 0 3}$ & $\mathbf{2 4 . 2 4} \pm \mathbf{2 . 8 5}$ & $\mathbf{1 0 . 3 7 \pm \mathbf { 1 . 7 8 }}$ & $\mathbf{6 . 9 9} \pm \mathbf{1 . 4 5}$ \\
\hline
\end{tabular}


Table 3: Axial Variation of Vessel and Ray Characteristics of Boscia angustifolia Wood

\begin{tabular}{|c|c|c|c|c|}
\hline SH & RP & VD (mm) & RH $(\mu \mathrm{m})$ & RW $(\mu \mathrm{m})$ \\
\hline \multirow{3}{*}{ TOP } & Outer & 68.41 & 324.19 & 42.16 \\
\hline & Middle & 63.38 & 324.19 & 39.68 \\
\hline & Inner & 50.01 & 286.49 & 40.71 \\
\hline Mean & & 60.59 & 309.11 & 40.85 \\
\hline \multirow{3}{*}{ MIDDLE } & Outer & 72.33 & 286.49 & 41.74 \\
\hline & Middle & 65.92 & 361.89 & 40.30 \\
\hline & Inner & 75.02 & 361.89 & 40.53 \\
\hline Mean & & 71.09 & 331.73 & 40.85 \\
\hline \multirow{3}{*}{ BASE } & Outer & 59.93 & 218.64 & 60.97 \\
\hline & Middle & 77.70 & 233.72 & 94.25 \\
\hline & Inner & 57.87 & 256.33 & 43.63 \\
\hline Mean & & 65.17 & 241.25 & 66.26 \\
\hline P. Mean & & $65.61 \pm 8.64$ & $294.65 \pm 14.12$ & $49.32 \pm 19.23$ \\
\hline
\end{tabular}

Table 4: Radial Variation of Vessel and Ray Characteristics of Boscia angustifolia Wood

\begin{tabular}{ccccc}
\hline RP & SH & VD $(\mathbf{m m})$ & RH $(\boldsymbol{\mu m})$ & RW $(\boldsymbol{\mu m})$ \\
\hline \multirow{2}{*}{ OUTER } & Top & 68.41 & 324.19 & 42.16 \\
& Middle & 72.33 & 286.49 & 41.74 \\
Mean & Base & 59.93 & 218.64 & 60.97 \\
\multirow{2}{*}{ MIDDLE } & Top & 63.38 & 276.44 & $\mathbf{4 8 . 2 8} \pm \mathbf{9 . 4 8}$ \\
& Middle & 65.92 & 324.19 & 39.68 \\
& Base & $\mathbf{6 6 . 8 9} \pm \mathbf{6 . 1 0}$ & 361.88 & 40.30 \\
Mean & & $\mathbf{6 9 . 0 0 \pm 6 . 5 5}$ & 306.59 & $\mathbf{5 8 . 0 7} \pm \mathbf{2 9 . 7 1}$
\end{tabular}




\begin{tabular}{ccccc}
\hline \multirow{2}{*}{ INNER } & Top & 50.01 & 286.49 & 40.71 \\
& Middle & 75.02 & 361.89 & 40.53 \\
& Base & 57.87 & 256.33 & 43.63 \\
Mean & & $\mathbf{6 0 . 9 6} \pm \mathbf{1 0 . 9 4}$ & 301.57 & $\mathbf{4 1 . 6 1} \pm \mathbf{7 . 4 1}$ \\
P. Mean & & $\mathbf{6 5 . 6 1} \pm \mathbf{8 . 6 4}$ & $\mathbf{2 9 4 . 6 5 \pm \mathbf { 1 4 . 1 2 }}$ & $\mathbf{4 9 . 3 2} \pm \mathbf{1 9 . 2 3}$ \\
\hline
\end{tabular}

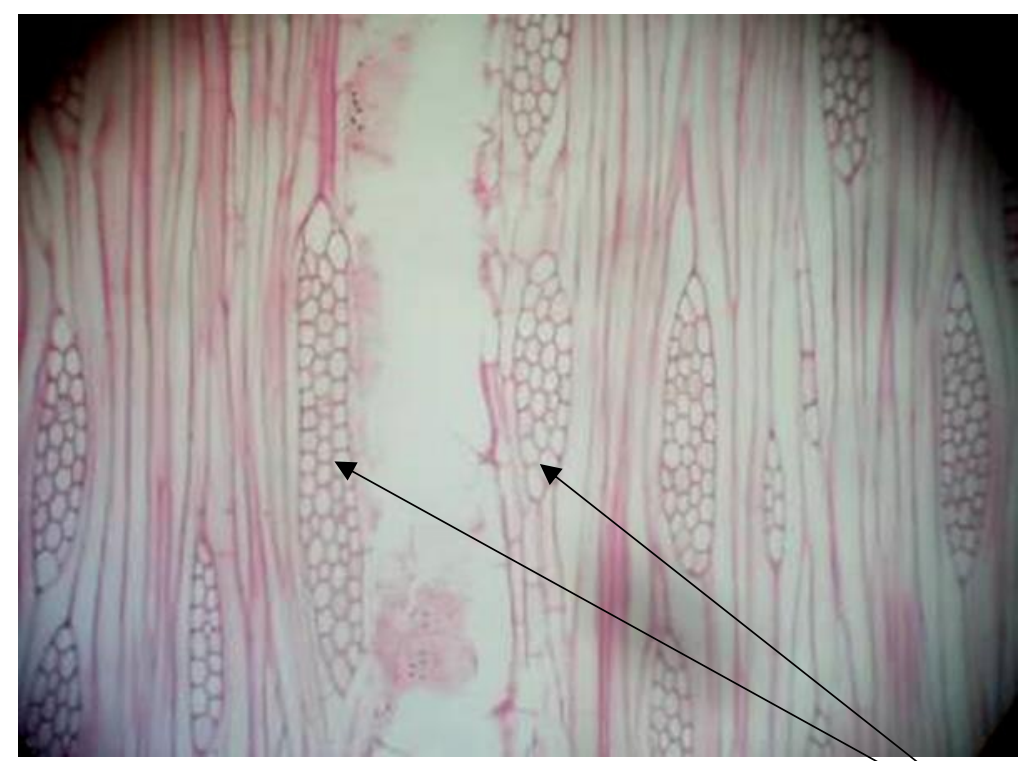

Fig. 1: Tangential view of Boscia angustifolia wood (Microscopic view)

Multi-seriate ray

The value of fibre length obtained in this study for Boscia angustifolia is still in the range of acceptable values for hardwood species known and used in Nigeria, in that G.arborea was reported to have a value of $1.29 \mathrm{~mm}$ as reported by Roger et al. (2007). Also, Oluwadare (2007) recorded $0.65 \mathrm{~mm}$ as fibre length of Leucaena leucocephala. However, according to Anon (1984), only fibre length $\geq 1.6 \mathrm{~mm}$ is considered as a long fibre. Therefore, it can be said that Boscia angustifolia does not have a long fibre. Thus, its utilization in the pulp and paper industry may be limited because longer fibres aid better paper resistance to tearing (Oluwadare and Sotande, 2007). Nevertheless, there was decrease in axial variation while radial variation shows an irregular trend. The pattern of variation exhibited along the sampling height (i.e top, middle, base) thus supports Hughes (1998). 
Also, fibre diameter for this species compared favourably with other selected wood species available in Nigeria. As reported by Adeniyi et al. (2013), Diospyros mespiliformis has fibre diameter of $17.41 \mu \mathrm{m}$, Tectona grandis $-33.40 \mu \mathrm{m}$, Triplochiton scleroxylon $-18.00 \mu \mathrm{m}$, Afzelia africana $23.60 \mu \mathrm{m}$, and Gmelina arborea - $38.60 \mu \mathrm{m}$. This implies that the characteristic functions of these species based on their fibre diameters can as well be attributed to wood of Boscia angustifolia. Furthermore, Adeniyi et al. (2013) in their work found a correlation between fibre diameter and runkel ratio. Runkel ratio is one of the indices considered for paper making. As such, Boscia angustifolia may still have a chance to be used in paper industry despite its limitation of its fibre length. However, irregular variation of fibre diameter was observed both axially and radially.

Values for lumen width in this study was also similar to the values of the selected wood species considered above. Adeniyi et al. (2013) found that lumen width was negatively correlated with runkel ratio and density. This correlation thus supports Hugo et al. (2009) stating that variation in wood density is mainly driven by variation in fibre lumen diameter which is directly related to cell size and to cell wall thickness. Based on the values revealed and correlation stated, Boscia angustifolia wood is expected to be a medium to large density wood, and as such can be considered for purposes requiring medium to large density.

Thickness of the fibre walls is one of the major factors that determines density and strength of a wood, such that thicker cell wall is expected to have a higher wood density and strength properties. The value of the cell wall thickness for the wood in study can be considered as medium to thick cell wall owning to its value. Wood with thicker cell wall are able to transmit more stress and thus, is good for heavy constructions. However, thick cell wall can inhibit the penetration of adhesive. Therefore, Boscia angustifolia may not be a good member for gluing. Also, Choong et al. (2000) stated that a wood with high specific gravity may result in poor gluability and low dimensional stability.

Wood with large pores such as having large vessel is generally light and also having coarse texture. Also, Karl (1984) reported that wood having large vessels may not be suitable for paper printing, reason being that more fillers will be needed to feel the vessels and other pores in the wood. Correlation analysis by Adeniyi et al. (2013) suggests higher density and strength properties for small vessels. With the values of vessel diameter obtained in this study, Boscia angustifolia can be concluded to have small vessels, thus affirming that Boscia angustifolia can be considered for structural purposes. The variation of vessel diameter along the axial plane and across the radial plane was irregular. This pattern of variation was similar to Karl (1984). 
As shown in Fig. 1, the rays of Boscia angustifolia is multi-seriate, which thus signifies that the wood is a hardwood. The ray height and ray width obtained in this study was lower to what was obtained for Tectona grandis (Ray height $-504 \mu \mathrm{m}$, Ray width - $59 \mu \mathrm{m}$ ) (Rahman et al., 2005). Hardwoods are generally characterized with very large rays, and such wider ray width contributes to the wood's aesthetic appeal. Thus, the values of the ray width obtained suggest an appealing aesthetic for Boscia angustifolia. Furthermore, Rahman et al. (2005) recorded that ray width is found to be closely related to ray proportion, and that ray proportion influences wood density and compression strength. That is, higher ray proportion consequently means higher specific gravity and compression strength. Therefore, a wider ray connotes higher strength properties and specific gravity.

However, Desch, H.E. and Dinwoodie, J.M. (2000) stated that broader ray is an indication that timber will spilt readily in a radial direction. Therefore, necessary consideration must be made to ensure a successful utilization of Boscia angustifolia wood.

\section{Conclusion}

This paper successfully access selected anatomical properties of Boscia angustifolia wood. Based on its findings, the anatomical properties of Boscia angustifolia compared favourably with other selected hardwood species commonly used in Nigeria. It also suggests a higher density and compression strength but poor gluability of this species. Thus, Boscia angustifolia can be used successfully for structural purposes.

\section{References:}

1. Anon, (1984). "Chemical Analysis of Nigerian Grown timbers". Annual Report of the Forestry Research Institute of Nigeria (FRIN). Jan- Dec pp 108-109.

2. American Society for Testing and Materials (ASTM) (2007). ASTM D1413-61 - "Preparation of decayed wood for microscopical examination”, ASTM International, West Conshohocken, PA, 2007

3. American Society for Testing and Materials (ASTM) (2007). ASTM D 1030-95 - "Standard test method for fibre analysis of paper and paperboard". West Conshohocken, PA. 2007.

4. Brian, M. (2010). "Mathew's wood anatomy and wood work characteristics of modern wood coatings". Wood Sci. and Tech. 32:347-365.

5. Burkill, H.M. (1985). "Boscia angustifolia A. Rich. (Family CAPPARACEAE)". The useful plants of west tropical Africa, Vol 1. Royal Botanic Gardens, Kew (K) 
6. Choong, E.T., Roliadi, H. and Chin, Y.H. (2000). "Wood properties of the Dipterocarpaceae". www.forestry, sarawak.gov.my/forweb.com

7. Desch, H.E. and Dinwoodie, J.M. (2000). "Timber: its structure, properties and utilization". $6^{\text {th }} \mathrm{Edn}$. Published by Macmillian Education, pg 410.

8. Dutt, D., Sharma, A. K., Agnihotri, S and Gautam, A. (2012). "Characterization of Dogs Tooth Grass and its Delignification by Soda Pulping Process". Journal of Science and Technology, 1: 434.

9. FAO (1998). "Non-wood forest products from conifers". Forestry Department.

10. Hickey, M. and King C. (2001). "Glossary of botanical terms". The Cambridge illustrated. Cambridge University Press.

11. Hugo, I. M.C., Cynthia S. J., Susana E. and Schenk, H.J. (2009). "Wood anatomy and wood density in shrubs: Responses to varying aridity along transcontinental transects". American Journal of Botany 96: 1388-1398 (2009), doi:10.3732/ajb.0800237.

12. IAWA (1989). "IAWA list of microscopic features for hardwood identification". By IAWA committee of the International Association of Wood Anatomist, edited by E.A. Wheeler, P.Baas \& P.E. Gasson

13. Karl, F. W. (1984). "Forestry Handbook", Society of American Foresters, Pp 616-623.

14. Oluwadare, A.O. (2007). "Wood Properties and Selection for Rotation Length in Caribean Pine (Pinus caribea Morelet) grown in Afaka, Nigeria”. Am-Eur. J. Agric. Environ. Sci., 2 (4): 359-363.

15. Oluwadare, A. O. and Sotannde, O. A. (2007). "The relationship between fibre characteristics and pulp-sheet properties of Leucaena leucocephala (lam.) De Wit". Middle-East Journal of Science Resources, 2(2): 63-68.

16. Poku, K., W. Qinglin and R. Vlosky, (2001). "Wood properties and their variations within the tree stem of lesser-used species of tropical hardwood from Ghana". Wood Fiber Sci. 33: 284-291.

17. Rahman M.M., Fujiwara S., Kanagawa Y., (2005): Variation in volume and dimension of rays and their effect on wood properties of Teak. Journal of wood and fibre science, July, 2005. Vol. 37(3). Pg. 497-504.

18. Roger M. R., Mario T. F. and Edwin C. A (2007). "Fibre morphology in fast growth Gmelina arborea plantations". Madera Bosques 13(2):3-13. 